\title{
Paget Schroetter syndrome imaged in multiple modalities and successfully treated with pharmacomechanical thrombectomy
}

\author{
James William Ryan, ${ }^{1}$ Alexandra Murphy, ${ }^{1}$ Sarah Wrafter, $^{2}$ Vinny Ramiah ${ }^{2}$
}

${ }^{1}$ Department of Radiology, Mater Misericordiae University Hospital, Dublin, Ireland ${ }^{2}$ Emergency Department, Mater Misericordiae University Hospital, Dublin, Ireland

Correspondence to Dr James William Ryan, jamesryannchd@gmail.com

Accepted 23 November 2016

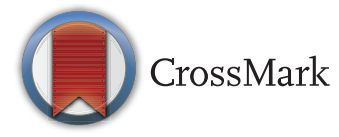

To cite: Ryan JW, Murphy A, Wrafter $S$, et al. BMJ Case Rep Published online: [please include Day Month Year] doi:10.1136/ bcr-2016-218238

\section{DESCRIPTION}

A young man in his early 30 s presented with a 3 -day history of left upper arm swelling and erythema (figure 1). He had no significant medical history. Of note he had a strong family history of deep venous thrombosis (DVT) with both parents having had lower limb DVTs. D-dimers were elevated, and the remaining laboratory investigations were within normal limits.

An upper limb Doppler ultrasound scan showed occlusive thrombus in the left subclavian vein

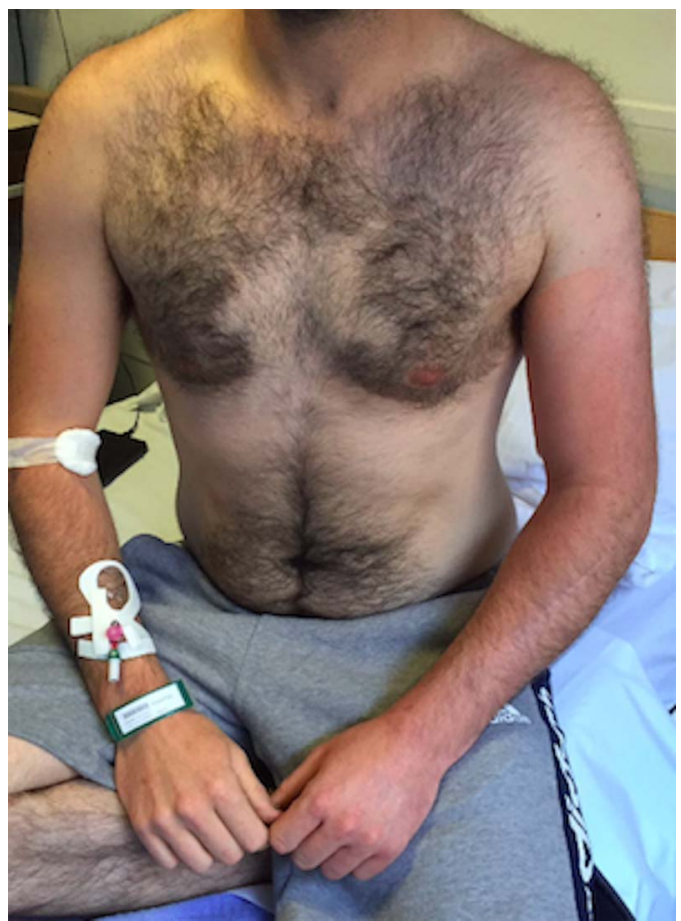

Figure 1 Erythematous, oedematous left upper limb.

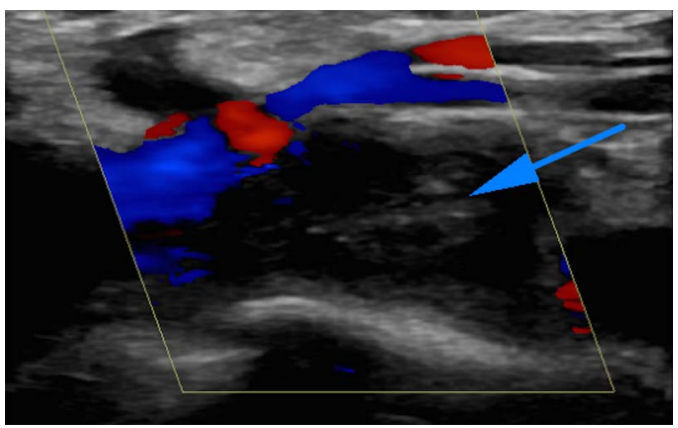

Figure 2 Doppler ultrasound scan. Blue arrow: occlusive thrombus in the left subclavian vein. (figure 2). A CT venogram further delineated the extent of the thrombus confirming the diagnosis of Paget Schroetter syndrome (figures 3 and 4). Subsequently, a conventional venogram was performed in conjunction with a therapeutic pharmacomechanical thrombectomy, which successfully restored flow in the left subclavian vein (figures 5 and 6).

Paget Schroetter syndrome, also known as effort thrombosis, is an uncommon disorder resulting in spontaneous subclavian venous thrombosis. Generally, it occurs in young and healthy adults. The subclavian vein is vulnerable to thrombosis due to its positioning relative to the first rib and clavicle. ${ }^{1}$

Signs of upper limb DVT should be investigated by Doppler ultrasound scan. However, if thrombosis is present within the non-compressible region of the clavicle, ultrasound may be falsely negative. ${ }^{2}$ MR or CT venogram is recommended if index of suspicion is high after a negative Doppler ultrasound scan. ${ }^{2}$

Management options include preadministration of thrombolytics prior to mechanical aspiration in

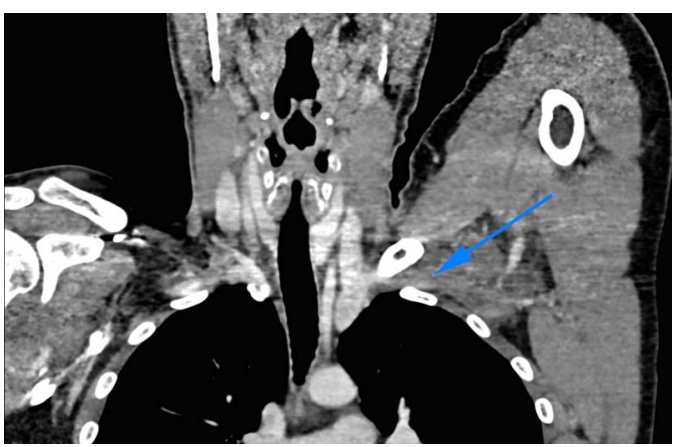

Figure 3 CT venogram coronal slice. Blue arrow: thrombus in the left subclavian vein.

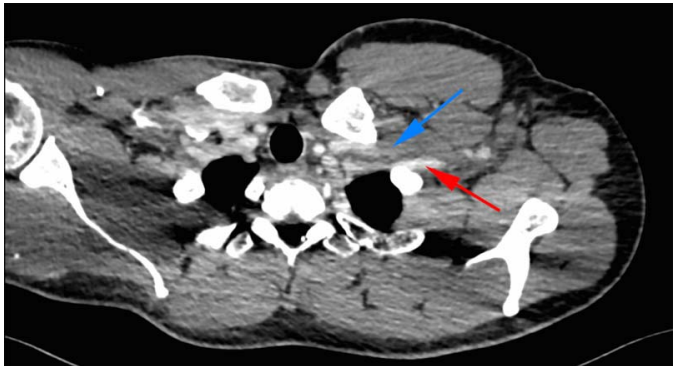

Figure 4 CT venogram axial slice. Blue arrow: occluded left subclavian vein. Red arrow: patent left subclavian artery. 


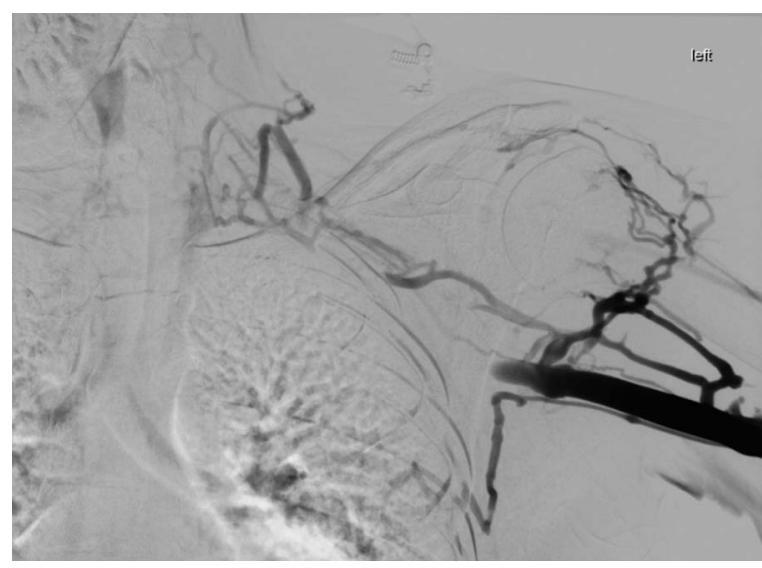

Figure 5 Venogram prethrombectomy.

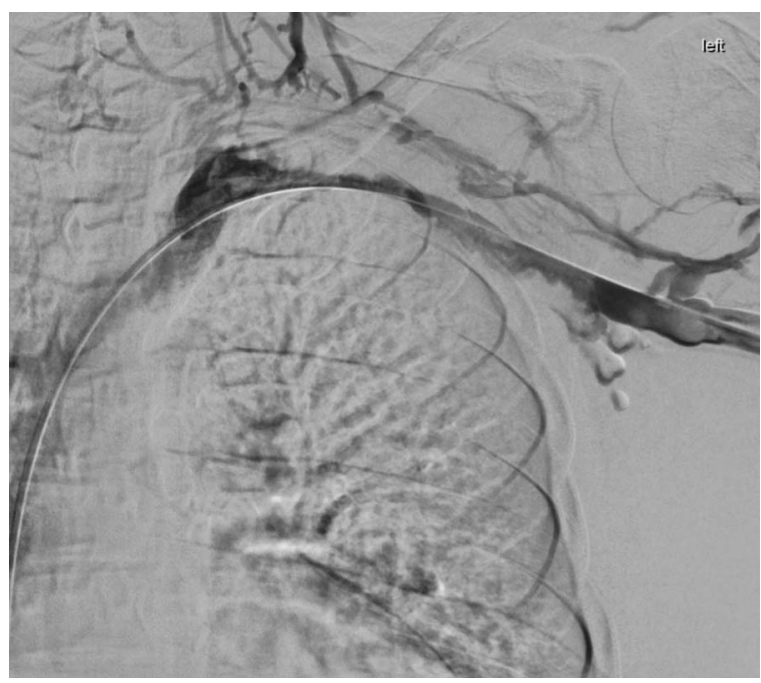

Figure 6 Venogram post-thrombectomy.

interventional radiology as in this case or therapeutic anticoagulation for 3-6 months. ${ }^{3}$ Thrombosis may recur in up to a third of patients if the predisposing venous impingement is not addressed. Surgical decompression of the subclavian vein is often performed to this end, for example, excision of the first rib. ${ }^{1}$ One study followed 50 patients who received thrombolysis followed by anticoagulation and no surgical intervention. Interestingly, it found that $82 \%$ of patients were asymptomatic at 57 months post-thrombolysis. ${ }^{1}$

\section{Learning points}

- Paget Schroetter syndrome is rare but should be ruled out in young patients presenting with signs and symptoms of upper limb deep venous thrombosis. ${ }^{1}$ Repetitive strain and subsequent subclavian vein impingement is thought to be the underlying aetiology.

- Doppler ultrasound scan can be falsely negative if thrombosis is present within the non-compressible region of the clavicle. ${ }^{2}$ If there is persistent clinical concern, a CT or MR venogram should be performed.

- Catheter-directed pharmacomechanical thrombectomy is usually successful if initiated within 14 days of thrombus formation. ${ }^{1}$ Post-thrombolytic surgical decompression of the subclavian vein is often performed to prevent future thrombosis; however, certain patients may remain symptom-free without surgical intervention.

Contributors JWR acquired and formatted images; submitted report, edited and added to body of text. AM wrote initial body of text draft. SW acquired patient consent, clinical information and image of patient. VR is Senior author and reviewed and approved the manuscript prior to submission.

Competing interests None declared.

Patient consent Obtained.

Provenance and peer review Not commissioned; externally peer reviewed.

\section{REFERENCES}

1 Illig KA, Doyle AJ. A comprehensive review of Paget-Schroetter syndrome. J Vasc Surg 2010;51:1538-47.

2 Jourdain V, Goldenberg WD, Matteucci M, et al. Paget-Schroetter syndrome: diagnostic limitations of imaging upper extremity deep vein thrombosis. Am J Emerg Med 2016;34:683.e1-3.

3 Norinsky AB, Espinosa J, Kianmajd M, et al. Painless acrocyanosis: Paget-Schroetter syndrome secondary to thoracic outlet obstruction from muscle hypertrophy. Am J Emerg Med 2016;34:1323.e1-3.

Copyright 2016 BMJ Publishing Group. All rights reserved. For permission to reuse any of this content visit

http://group.bmj.com/group/rights-licensing/permissions.

BMJ Case Report Fellows may re-use this article for personal use and teaching without any further permission.

Become a Fellow of BMJ Case Reports today and you can:

- Submit as many cases as you like

- Enjoy fast sympathetic peer review and rapid publication of accepted articles

- Access all the published articles

- Re-use any of the published material for personal use and teaching without further permission

For information on Institutional Fellowships contact consortiasales@bmjgroup.com

Visit casereports.bmj.com for more articles like this and to become a Fellow 